\title{
Endoscopic Management of Vesicoureteral Reflux in Duplex Renal Collecting Systems
}

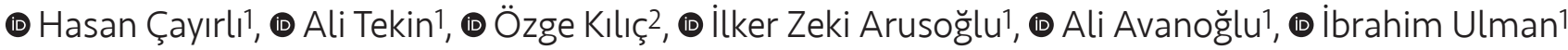

${ }^{1}$ Ege University Faculty of Medicine, Department of Pediatric Surgery, Division of Pediatric Urology, İzmir, Turkey

2Ege University Faculty of Medicine, Department of Pediatric Surgery, İzmir, Turkey

\begin{abstract}
Aim: Standardization of an optimal treatment protocol for vesicoureteral reflux (VUR) correlated with duplex kidney systems remains controversial. In this study, we reviewed our experience in endoscopic subureteric injection to correct reflux in duplex systems with documented indications, in an aim to confirm its position as an alternative means of open surgery.

Materials and Methods: The hospital records of complete renal duplex system patients who had experienced endoscopic subureteric injection for VUR between 2009 and 2018 were reviewed. The indications for the amelioration of VUR included breakthrough urinary tract infection (UTI) along with the presence of renal scarring.

Results: A total of 24 patients ( 18 girls, 6 boys) with refluxing renal duplex systems were included in the study. The mean age at first injection was $46.4 \pm 28.8$ months (5-160) and the mean duration of follow-up was $47.25 \pm 27.7$ months. The success rate with the initial injection was $83.3 \%$ (20/24). The mean volume of material injected was $0.68 \pm 0.49 \mathrm{~mL}$ per duplex system.

Conclusion: Management of reflux in duplex systems is still controversial with insufficient data. Our results suggest that endoscopic management should be considered as an alternative to open ureteral reimplantation in refluxing duplex renal collecting systems. Major open surgery and accompanying discomfort can be avoided by an endoscopic injection which can be performed as an outpatient procedure in most of the reflux patients with duplex system who have an indication for surgical management.
\end{abstract}

Keywords: Vesicoureteral reflux, duplex renal systems, endoscopic reflux treatment, subureteric injection, pediatric

\section{Introduction}

The management of vesicoureteral reflux (VUR) in complete renal duplex systems remains a controversial issue. In this patient group, the spontaneous resolution of VUR (1), urinary tract infection (UTI) incidence $(2,3)$, reflux grade, and the success of surgical treatment $(4,5)$ are affected by certain anatomic factors. Endoscopic management of VUR has reached worldwide popularity because it is easy to apply, and has short hospital stay with superior patient comfort in children, with the inclusion of duplex systems
(6-9). In this study, we reviewed our experience in an aim to evaluate the safety and efficacy of endoscopic subureteric injection to correct VUR in complete duplex systems with documented indications for anti-reflux surgery.

\section{Materials and Methods}

The hospital records of complete renal duplex system patients who underwent endoscopic subureteric injection for VUR between 2009 and 2018 were reviewed. Those patients with partial duplication of the ureter(s) or documented bladder-sphincter dysfunction were excluded. 
The indications for VUR correction included breakthrough UTI or the existence of renal scarring. Breakthrough UTI was defined as one with fever $\left(>38^{\circ} \mathrm{C}\right)$ and proven with a catheter collected urine culture that happened during a course of antibiotic prophylaxis. Lower UT (LUT) functions were evaluated by detailed anamnesis (such as constipation, storage/voiding symptoms), voiding frequency/volume chart, uroflow studies, bladder wall thickness, and post-void residual measurement for those children who had voluntary control over their LUT function. If the child was $<5$ years of age and did not have voluntary control, LUT function was accepted as normal if the bladder wall thickness and post-void residual measurements were in range. Invasive urodynamic studies were not routinely used to evaluate LUT function. All families were informed about VUR treatment options and the expectations regarding their success rates in duplex systems. The choice of an open or endoscopic method was left to the family as a treatment method. Those who elected for open surgery were not included in this study. Informed consent was obtained from the parents/ legal guardians of the patients before the procedure. Data including preoperative and postoperative VUR grades, the presence of contralateral VUR, the presence of ureterocele, the site of refluxing renal moiety, the amount of injected material, patient demographics, and the success rates following endoscopic treatment were recorded.

Reflux classification was made according to the International Reflux Study in Children, also known as the International Classification (10). The procedure was performed via $9.5 \mathrm{Fr}$., $0^{\circ}$ cystoscope (Storz, Tuttlingen, Germany) undergeneral anesthesia. Polyacrylatepolyalcohol copolymer (PPC) (Vantris ${ }^{\circledR}$, Promedon, Argentina) was applied submucosally at the most suitable position(s) of the ureteral orifices until the creation of a significant bulge using a Williams cystoscopic injection needle (Cook Medical ${ }^{\circledR}$, Bloomington, USA). A standard method was not applied for subureteric injection, and injections were made at the appropriate place(s) and in the appropriate number according to the anatomical features. All procedures were performed according to the outpatient protocol and complete resolution of reflux in voiding cystourethrogram (VCUG) obtained at least three months after injection was defined as the success criterion. If persistent reflux was detected, the injection was repeated, or open surgery was performed depending on clinical features and parental choice.

Ultrasound examinations were carried out at the first, third, and sixth months for post-operative control, and afterward, performed yearly for the follow-up of findings such as increased or newly developed hydroureteronephrosis suggesting obstruction. The approval for this study was obtained from the Ethics Committee of Ege University Faculty of Medicine, under the number 20-5.1T/27.

\section{Results}

Twenty-four patients (18 girls, 6 boys) with refluxing duplex kidneys were involved in the study. The mean age was $46.4 \pm 28.8$ months (5-160) at first injection, and the mean duration of follow-up was $47.25 \pm 27.7$ months. Pre-operative scintigraphic examination revealed a loss of function in 14 patients and localized scarring in 6 patients. The success rate with the initial injection was $83.3 \%$ (20/24). The success rates for grade IV and grade $\mathrm{V}$ reflux in duplex systems were $80 \%$ and $83.3 \%$, respectively. The mean material volume injected was $0.68 \pm 0.49 \mathrm{~mL}$ per duplex system at the first injection. A flowchart showing the overall management steps for the study group is summarized in Figure 1.

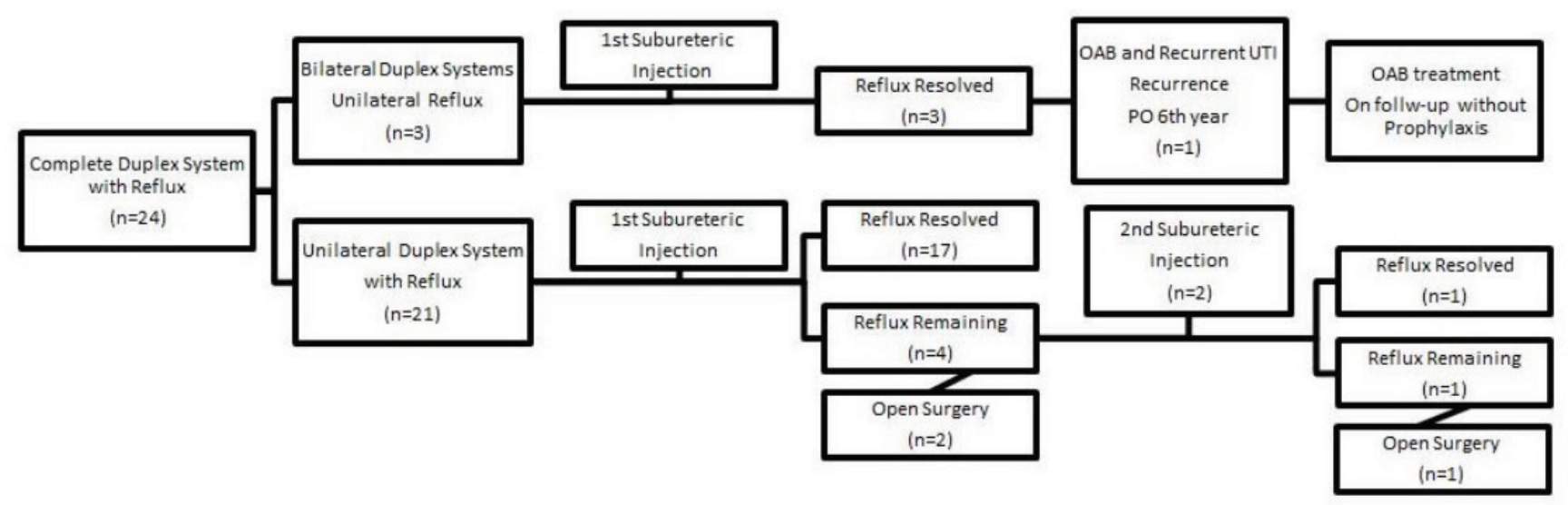

Figure 1. The steps of overall management for the study group

$O A B$ : Overactive bladder, UTI: Urinary tract infection 
Twenty-one of the 24 patients had unilateral, and 3 had bilateral duplex systems with unilateral reflux. Fourteen patients had reflux to the left and 10 patients to the right kidney. Eighteen patients had reflux to the lower moiety, one patient only had reflux to the upper moiety, and 5 patients had reflux to both upper and lower moieties. Six ureters had grade $V$ reflux, 10 had grade IV reflux, 8 had grade III reflux, and 5 had grade II reflux. Twelve patients had a unilateral refluxing duplex system coexisting with contralateral reflux into a single system, and all refluxing units were treated successfully with a single injection in these patients.

Twenty of the 24 patients (83.3\%) were treated successfully at the first injection. Two of 4 patients were treated with a second endoscopic subureteric injection, and only one of these succeeded. Two of the 4 patients whose first subureteric injection failed had metachronous contralateral reflux. Eventually, 3 patients had an open surgical procedure for persistent VUR. In these cases, ureteroneocystostomy was performed in line with the choices of the families. During the open surgeries, subureteric injection materials did not complicate ureteric dissection.

Two of the patients had incised ureteroceles, and reflux (one to the upper moiety and the other one to the lower moiety) was treated successfully with the first subureteric injection in both cases. One of them had recurrent UTI in the postoperative $6^{\text {th }}$ year. She also had complaints of overactive bladder (OAB). VCUC revealed recurrent grade III VUR to the upper moiety. OAB was treated with anticholinergics, and she did not have any subsequent UTI on the follow-up without prophylaxis. Our patients did not have gross hematuria or urinary retention, and neither early post-operative febrile UTI episodes nor new-onset hydronephrosis were seen on follow-up.

\section{Discussion}

Renal duplication, which is the UT's most common congenital abnormality, has an incidence of $0.8 \%$ to $2 \%$ (3 $4,11,12)$. Duplex systems can be associated with nearly $8 \%$ of children admitted to the hospital with febrile UTIs $(9,13,14)$, and VUR is present in $70 \%$ of these children $(2-4,12)$. VUR has an incidence of $56 \%$ in patients with a duplex system and occurs in the lower moieties in $75 \%$ of cases (1). As compatible with the literature, 18 of 24 patients (75\%) had reflux into the lower moiety in our study.

In VUR patients, long-term antibiotic prophylaxis is not without concerns, such as increased bacterial resistance, and a high rate of recurrent UTI $(1,4,15)$. On the other hand, the spontaneous resolution rate, especially of high-grade VUR in duplex systems, is lower in comparison to single renal systems due to the anatomic configuration of the region $(1,4,7,8)$, and these patients have a greater likelihood of recurrent UTI and renal parenchymal scarring $(4,8,13)$. Hunziker et al. (4) reported a febrile UTI rate of $4.1 \%$ in their study, with Dextranomer/Hyaluronic acid (Dx/HA) injection for VUR in duplex system patients. In our study, one patient (4.1\%) had recurrent febrile UTI in the follow-up, and she was the only patient who had new renal scarring and long-term recurrence of VUR despite initially successful endoscopic treatment.

While open surgery is accepted as the gold standard with a success rate of over $95 \%$, it is more complex and carries a higher risk of complications than for singlesystem cases due to anatomical variations $(8,16)$. Similar to those with single-system reflux, the advantages of the STING procedure in a refluxing duplex system are that it can be performed with a short anesthesia time and is well tolerated so that it can be performed as an outpatient procedure $(6,7,16)$. STING is currently recommended for use in complex VUR, including duplex systems (16). In our study group, breakthrough UTI and renal parenchymal scarring were the indications for surgical treatment. The families were informed about open and endoscopic surgical techniques, and they were allowed to decide on the surgical treatment method.

There are controversies regarding endoscopic treatment. Repeated injections for unsuccessful attempts increase the number of anesthesia sessions. Furthermore, its success rate may decrease with time, and the treatment may even become ineffective at long-term follow-up (16). In a multicenter trial, between 6 months and 3 years, the late recurrence rate was $21 \%$ after subureteric Dx/HA injection for VUR treatment $(17,18)$. Only one of our patients who presented with $O A B$ and recurrent UTI complaints and was treated medically had recurrent reflux during 6 years of follow-up. Since we do not perform routine VCUG in our patients without symptoms during long-term follow-up, we cannot give a figure regarding reflux recurrence rates over a long-term in our series.

The overall ratio of VUR resolution increases with multiple endoscopic injections (9). In our series, the families of 4 patients with unsuccessful first injections were given repeat injection or open surgery options. Only two families preferred the second injection, and the other two preferred open surgery. One of the two patients was successfully treated with a second injection, and the other patient 
needed open surgery after the second failure via injection. The resolution rate of reflux in our patients was $83.3 \%$ (20 of 24 patients) after the first injection and this increased to $87.5 \%$ after the second injection.

In a systemic review of published studies on the endoscopic management of VUR in patients with the duplex systems, the predicted probability of success was reported to be $68 \%$ for the single system and $64 \%$ for the duplex system $(4,8)$. In our series, the success rate with the first injection was higher than for similar studies in the literature. Since subureteric injections in our patients were not performed by a single surgeon or with a standardized method, the reason for this high success may be related to the injected material.

Kocherov et al. (19), in a multicenter survey study, found the success rate to be $93.8 \%$ (759 of 809 renal units) after the first PPC injection, including both primary and complex VUR patients. Furthermore, Tekin et al. (20) obtained a higher success rate for the first injection in the PPC group (90.5\%) than in the Dx/HA group (62.4\%) in their study which included 260 primary and secondary VUR patients. These high success rates published in the literature show that our high success rates in endoscopic VUR treatment in duplex systems may be related to the material used for subureteric injection. Although PPC is known to have a relatively high success rate in the treatment of endoscopic VUR, postoperative obstruction was also reported in relation to the amount of material used (above $2 \mathrm{~mL}$ ) at a rate of $11 \%$ requiring treatment and $5.6 \%$ requiring open surgical treatment in the study of De Badiola et al. (21) in 2013. The postoperative obstruction rate was only $0.7 \%$ after subureteric injection of Dx/HA up to $1 \mathrm{ml}$ in the study of Vandersteen et al. (22) in 2006. Urinary obstruction was not observed in any of our patients in the follow-up of mean 47 months; thus, the mean volume injected per duplex system was $0.68 \mathrm{~mL}$ in our study. Hunziker et al. (4) reported the success rate to be $67.2 \%$ with grade IV and $45.5 \%$ with grade $V$ reflux in complete duplex systems. In our study, the success rate for grade IV reflux in duplex systems was $80 \%$, and for grade $V$ reflux, it was $83.3 \%$. These high success rates support the idea that subureteric injection therapy can be preferred in duplex system patients with high-grade reflux. Moreover, in 5 patients with upper and lower moiety reflux, the success rate was as high as $80 \%$ with the first injection and $100 \%$ with the second.

\section{Study Limitations}

Our study has some limitations. It was a retrospective study and we did not have a control group. In duplex systems, the distance between the anatomic features and the location of duplicated ureteral orifices may differ. Although the puncture site of the needle can be standardized in the STING method for single system ureters, this is not easy to achieve for duplex systems. The injection number per operation or method could not be analyzed statistically in this study due to the low number of patients in the groups.

Although there are studies with higher patient numbers, the high success rate of our study is noteworthy $(3,6)$. While the parents were routinely informed, the possibility that some parents did not report the occurrence of febrile UTI after recovery from VUR should be considered. Prospective randomized studies are required to confirm our results.

\section{Conclusion}

The management of reflux in duplex systems is still controversial and there is insufficient data. Our results suggest that endoscopic management should be considered as an alternative to open ureteral re-implantation in refluxing duplex renal collecting systems. Major open surgery and its accompanying discomfort can be avoided by an endoscopic injection, which can be performed as an outpatient procedure in most reflux patients with a duplex system who have an indication for surgical management.

Acknowledgements: The authors certify that they have no affiliations with or involvement in any organization or entity with any financial or non-financial interest in the subject matter or materials discussed in this manuscript.

\section{Ethics}

Ethics Committee Approval: The study was approved by the Ethics Committee of Ege University Faculty of Medicine (approval date: 29.05.2020; approval no: 20-5.1T/27).

Informed Consent: Informed consent was obtained from the parents/legal guardians of the patients.

Peer-review: Externally peer-reviewed.

\section{Authorship Contributions}

Concept: H.Ç., A.T., Design: H.Ç., I.U., Data Collection or Processing: Ö.K., I.Z.A., H.Ç., Analysis or Interpretation: A.T., A.A., i.U., Literature Search: H.Ç., I.U., Writing: H.Ç., A.T., i.U..

Conflict of Interest: The authors declare that they have no conflict of interest.

Financial Disclosure: The authors declared that this study received no financial support. 


\section{References}

1. Bartoli F, Niglio F, Pastore V, et al. Polydimethylsiloxane (macroplastique) injection for vesicoureteral reflux in duplex ureters: A comparison with single renal systems. J Pediatr Urol 2011; 7:516-9.

2. Thomas JC. Vesicoureteral reflux and duplex systems. Adv Urol 2008; 2008:651891.

3. Privett JT, Jeans WD, Roylance J. The Incidence and Importance of Renal Duplication. Clin Radiol 1976; 27:521-30.

4. Hunziker M, Mohanan N, Puri P. Dextranomer/Hyaluronic Acid Endoscopic Injection is Effective in the Treatment of Intermediate and High Grade Vesicoureteral Reflux in Patients with Complete Duplex Systems. J Urol 2013; 189:1876-81.

5. Elder JS, Peters CA, Arant BS Jr, et al. Pediatric Vesicoureteral Reflux Guidelines Panel Summary Report on the Management of Primary Vesicoureteral Reflux in Children. J Urol 1997; 157:1846-51.

6. Steinbrecher HA, Edwards B, Malone PS. The STING in the Refluxing Duplex System. Br J Urol 1995; 76:165-8.

7. Miyakita H, Ninan GK, Puri P. Endoscopic Correction of VesicoUreteric Reflux in Duplex Systems. Eur Urol 1993; 24:111-5.

8. Hensle TW, Reiley EA, Ritch C, Murphy A. The clinical utility and safety of the endoscopic treatment of vesicoureteral reflux in patients with duplex ureters. J Pediatr Urol 2010; 6:15-22.

9. Rossini (), Moriarty KP, Courtney RA, Tashjian DB. Endoscopic Treatment With Deflux for Refluxing Duplex Systems. I Laparoendosc Adv Surg Tech A 2009; 19:679-82.

10. Weiss RA, Spitzer A. Vesicoureteral Reflux and Reflux Nephropathy. In: Suki WN, Massry SG (eds). Suki and Massry's therapy of renal diseases and related disorders. Boston, MA, Springer, 1998.

11. Molitierno JA Jr, Scherz HC, Kirsch AJ. Endoscopic injection of dextranomer hyaluronic acid copolymer for the treatment of vesicoureteral reflux in duplex ureters. I Pediatr Urol 2008; 4:372-6.

12. Hunziker M, Mohanan N, Menezes M, Puri P. Prevalence of duplex collecting systems in familial vesicoureteral reflux. Pediatr Surg Int 2010; 26:115-7.
13. Bisset GS 3rd, Strife IL. The Duplex Collecting System in Girls With Urinary Tract Infection: Prevalence and Significance. AJR Am J Roentgenol 1987; 148:497-500.

14. Visuri S, Jahnukainen T, Taskinen S. Prenatal complicated duplex collecting system and ureterocele-Important risk factors for urinary tract infection. J Pediatr Surg 2018; 53:813-7.

15. Hensle TW, Grogg AL. Part 1: Vesicoureteral reflux treatment: The past, present, and future. Curr Med Res Opin 2007; 23(Suppl 4):1-5.

16. Yu TJ, Chang LC. Use of Collagen for Endoscopic Correction in Complicated Vesicoureteral Reflux. Scand I Urol Nephrol 2007; 41:58-65.

17. Schmedding A, Zeeh $U$, Huebner U, Krause M, Lorenz C. Sx IN - Prospective multicenter survey of subureteric injection in children. Presented at international conference on vesicoureteral reflex in children, June 4e6, Goteborg, Sweden, 2009.

18. Chertin B, Kocherov S. Long-term results of endoscopic treatment of vesicoureteric reflux with different tissueaugmenting substances. J Pediatr Urol 2010; 6:251-6.

19. Kocherov S, Ulman I, Nikolaev $\mathrm{S}$, et al. Multicenter Survey of Endoscopic Treatment of Vesicoureteral Reflux Using Polyacrylate-Polyalcohol Bulking Copolymer (Vantris). Urology 2014; 84:689-93.

20. Tekin A, Yagmur I, Tiryaki S, Dokumcu Z, Ulman I, Avanoglu A. Changing bulking agent may require change in injection volume for endoscopic treatment of vesicoureteral reflux. Int Braz I Urol 2018; 44:1194-9.

21. De Badiola $\mathrm{Fl}$, Soria $\mathrm{R}$, Vagni RL, Ormaechea MN, Moldes JM, Benmaor C. Results of Treatment of Grades IV and V Vesicoureteral Reflux with Endoscopic Injection of Polyacrylate Polyalcohol Copolymer. Front Pediatr 2013; 1:32.

22. Vandersteen DR, Routh JC, Kirsch AJ, et al. Postoperative ureteral obstruction after subureteral injection of dextranomer/ hyaluronic Acid copolymer. J Urol 2006; 176:1593-5. 